\title{
Contribution of Iranian scholars to medical sciences: A holistic overview of 140-years publication
}

\author{
Shahram Sedghi ${ }^{1,2}$, Maryam Razmgir*2 (D), Mina Moradzadeh*2,3 (D) \\ Received: 15 Apr 2019 \\ Published: 23 Nov 2020
}

\begin{abstract}
Background: This study investigated the trends in the scientific output of Iran published in PubMed indexed journals. To the best of our knowledge, there was no previous study to examine the Iranian scientific output in all fields of health and biomedical sciences.

Methods: Using a bibliometric approach, we tracked 140 years (between 1877 and 2016) of Iranian scientific productions in PubMed. The journals which papers widely published over them were analyzed. The metadata of journals was extracted from Web of Science (WoS), Scopus, and Scimago Journal \& Country Rank. The Gross Domestic Product (GDP) data was elaborated from the World Bank to evaluate the relationship with research output. We used Pearson's correlation coefficient at $\mathrm{p}<0.01$ significance level and reported the data in a scatterplot.

Results: We identified 106226 documents produced by Iranian authors in journals indexed in PubMed since 1877. The number of papers climbed dramatically in 2000 and afterward, and this was consistent with the country's GDP. Although the scientific contribution of Iranian researchers is remarkable, 67\% of papers (26 978 out of 106226 ) were published in local Journals categorized into quartile 3 and 4 of WoS and Scopus. The study shows that GDP growth has had a positive influence on publication output $(\mathrm{r}=0.738, \mathrm{p}<0.001)$.

Conclusion: This is the first study with a panorama view of Iran's contribution to biomedical literature. Based on the results of our survey, although the number of Iranian publications rose over time but they are mostly published in low ranked journals. Health policymakers advise reconsidering the criteria for measuring research activities. Improving policies will help researchers to publish in higher ranked journals.
\end{abstract}

Keywords: Publications, Publishing trend, Scientific production, Iran, PubMed, Gross domestic product, GDP

Conflicts of Interest: None declared

Funding: None

*This work has been published under CC BY-NC-SA 1.0 license.

Copyright $\odot$ Iran University of Medical Sciences

Cite this article as: Sedghi Sh, Razmgir M, Moradzadeh M. Contribution of Iranian scholars to medical sciences: A holistic overview of 140-years publication. Med J Islam Repub Iran. 2020 (23 Nov);34:158. https://doi.org/10.47176/mjiri.34.158

\section{Introduction}

Publishing via scientific journals is the main channel to disseminate research results. After publication, results are used by other researchers in related studies, the article receives citations, and this process is continuing (1). The number of citations received by an article is a dominant measure of authors' and journals' performance and quality

Corresponding author: Maryam Razmgir, razmgir.m@iums.ac.ir

Mina Moradzadeh, moradzadeh.mina@iums.ac.ir

1. Health Management and Economics Research Center, Iran University of Medica Sciences, Tehran, Iran

2. Department of Medical Librarianship and Information Sciences, School of Health Management and Information Sciences, Iran University of Medical Sciences, Tehran, Iran

3. Health Services Management Research Center, Institute for Futures Studies in Health, Kerman University of Medical Sciences, Kerman, Iran
(2). Accordingly, researchers consider metrics including impact factor (IF) to select journals not only for publishing their articles but also for reading and citing documents (3). Moreover, measurements and evaluations are required to analyze the quality of publications and to improve scientific productivity at the international level (4).

\section{$\uparrow$ What is "already known” in this topic:}

There are many studies reported the biomedical research outputs of Iran over a limited range of years; however, there is no big picture for the country's publishing trend.

\section{$\rightarrow$ What this article adds:}

This study has a panorama view of the biomedical production trend in Iran. The findings show the increasing rate in the number of publications. However, the Iranian authors mostly tend to publish in low ranked Middle Eastern journals, typically local ones. 
Publishing in prestigious journals indexed in sound databases such as Web of Science (WoS), Scopus, and PubMed represents the quality of articles. Moreover, the literature suggests that the papers published via high ranked journals receive more citations compared to others (5-7). Accordingly, analyzing the scientific productivity of scientists at the national level makes it possible not only to evaluate publication activity, but also to predict further methods for the development of science and technology.

$\mathrm{Gul}$ et al. investigated the scientific productivity of Middle Eastern countries. They retrieved 1187872 papers published by Middle Eastern scientists in journals indexed by Science Citation Index (SCI) in the WoS platform between 1945 and 2014. The authors reported that Israel had the highest number of papers followed by Turkey and Iran (8, 9).

With a rapid growth rate of publication, Iran leaves other fast-developing countries in the dust. For instance, Kharabaf and Abdollahi reviewed scientific output in Iran and reported that Iran accounted for 20610 publications indexed ISI journals in Thomson Reuters in 2010 (10). While, according to Osareh and Wilson, only a single Iranian paper was published in SCI-indexed journals in 1972, whereas; the number of papers produced by the Iranian authors reached to 610 by the end of 1978 (11). Iranian authors tripled their scientific output from 501 articles in 1996 to 1 830 in 2002 (12). Naghizadeh and Naghizadeh examined the scientific contribution of Iranian authors. Their findings indicated that Iran acquired $17^{\text {th }}$ world-wide ranking with 51187 items in 2016 and achieved $18^{\text {th }}$ international ranking in the number of citations (28 965) received based on the Scopus database (13). Saboury studied Iranian publications in WoS from 1993 to 2002 and compared the production status of Iran with selected countries. He concluded that the share of Iran's scientific outputs had been increased from 0.015 in 1993 to 0.217 in 2002 (14).

Moein et al. evaluated the scientific output of Iran from 1967 to 2003 and compared with other 15 countries; they showed the relative share of Iran in the scientific output increased from $0.0003 \%$ in 1970 to $0.29 \%$ in 2003 in the world and it stands on the $13^{\text {th }}$ place among the selected countries (15). As evidence shows, despite there were an increasing rate in Iranian publications; however, citations did not seem to correspond to the growth rate (16).

Sadeh et al. reported the scientific output of Iran from 1997 to 2018 in Scopus. They reported that Iran stands in the twenty-first place in the global scientific publication ranking. Although $22 \%$ of papers were published in the health and biomedical field, the average ranks of source journals showed a significant and consistent drop (17).

To sum up, the scientific productivity of Iran increased significantly over time; however, to the best of our knowledge, there have been no big picture for Iranian biomedical publication.

PubMed is the largest open-access database for biomedical literature that comprises more than 28 million citations from Medline, life science journals, and online books. It is worth noting that major medical journals are indexed in PubMed and more than 2 billion searches are performed each year via PubMed. Thus, it is an essential database for researchers dealing with health-related subjects.

To sum up, the scientific productivity of Iran increased significantly over time; however, to the best of our knowledge, there have been no reports of Iranians publication trends in PubMed. Therefore, we investigated the country affiliated publication in PubMed to draw the overall picture of Iranian medical scientists' publications. Moreover, we studied the number of publications, the status of journals in citation databases, and the association between Gross Domestic Product (GDP) and research output.

\section{Methods}

This study conducted to investigate the scientific productivity of Iranian scholars in PubMed and examine the status of journals that the Iranian papers mostly published over them. Thus, the search was carried out using "Iran" OR "Persia" (the former and ancient name for Iran before the $20^{\text {th }}$ century) syntax in the PubMed affiliation field from inception to December 2016. The data were collected in Jan 2018. All of PubMed publication types were included except book and book chapters $(18,19)$. In total, 106226 publications were retrieved and included in the analysis, among which 2582 were "in press".

Noteworthy, in 6 out of 106226 papers, the country name in affiliations was "Persia" and for the remaining papers (106 220) authors used "Iran". We exported the data of all articles from PubMed into XML file format and converted to Microsoft Excel to perform the analysis.

We extracted the title of source journals and counted the number of articles for each journal to identify the top 100 journals with the highest number of articles (Appendix 1).

The details of top 100 source journals, which have published the most Iranian papers, including full name, ISSN, country of publisher, category (we mentioned the $1^{\text {st }}$ category of Scopus), CiteScore, Percentile, Quartile (Q) and IF were obtained from the NLM catalog, Scopus, WoS, and Scimago Journal \& Country Rank databases. We found that 8 out of the top 100 source journals were Iranian based on the publishers; however, published in a different country, 7 journals published in Netherlands and 1 journal in the UK; we considered them as Iranian journals.

Since the GDP is the key indicator for the economic strength of a country and it is related to the amount spent on research and development and effects on the scientific growth (20), we extracted the GDP data from the World Bank. We used Pearson's correlation coefficient at $p<0.01$ significance level to evaluate the correlation of GDP and the publication productivity. The data was analyzed by SPSS 22.0 and the results reported with a scatterplot.

\section{Results}

\section{Overview of Iranian Scholars Publication and GDP}

In total, 106226 papers were identified in PubMed published by Iran until the end of 2016. The first paper was authored by Dr. Lucas in 1877 and published in "The Indian Medical Gazette" journal entitled "Case of Scleroderma" who used the "Her Majesty's Bombay Army, Civil Surgeon, Bushire, Persia" as affiliation (21). Iranian authors published 6 papers until 1922. These papers used Persia as the affiliation. No article was found in PubMed authored by 


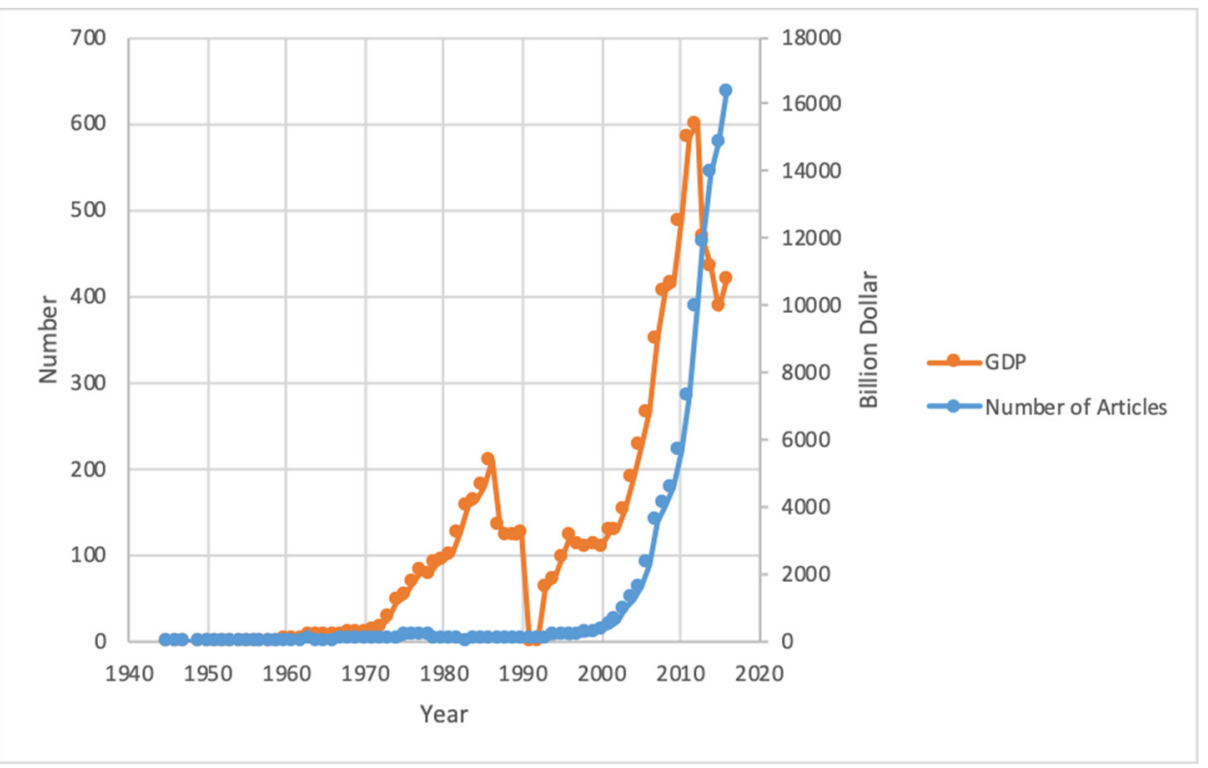

Fig. 1. Comparison of Iranian articles in PubMed with GDP trend 1945-2016

Iranian between 1922 and 1944, and after 22 years, only one paper was published in 1945 . The first paper that mentioned "Iran" as affiliation was written in 1954 by M. Baltazard and M. Ghodssi from "Institut Pasteur of Iran" entitled "Prevention of Human Rabies; Treatment of Persons Bitten by Rabid Wolves in Iran", published in "Bulletin of the World Health Organization" journal (22). The number of publications had increased dramatically after 2000 (Fig. 1).

We obtained the GDP data from the World Bank (23) to examine whether there was any association between the country research productivity and its GDP. Figure 1 presents an overview of Iranian publications and GDP trends during the investigated period. Likewise, the number of publications and the overall GDP rate increased throughout the years.

Although, there was a fall in the mid 1980s since the oil price dropped drastically, and this impressed the GDP in Iran and other oil-producing countries.
2. Analysis of Top 100 Contributing Journals to the Iranian Papers

This is worth mentioning that Iranian papers were published in 5625 journals indexed in PubMed. The top 100 source journals were selected based on the number of papers published. We found that $38 \%$ of papers (40 160 out of 106226 ) had been published in these 100 journals.

Analysis of the regional distribution for source journals showed that 61 journals from 100 titles are based in Middle Eastern countries, 23 journals in European Union, 7 journals in Northern America, and 9 in other countries (Fig. 2). Fifty-nine of these 100 journals were published in Iran while 41 were published in other countries (Fig. 3).

$2.1 \mathrm{Web}$ of Science analysis: Findings revealed that 71 of the top 100 source journals were indexed in WoS; however, only 51 of the journals had an IF based on Journal Citation Report (JCR 2016). The IF of 32 journals (out of 51) were higher than 1.00 according to data obtained from the WoS

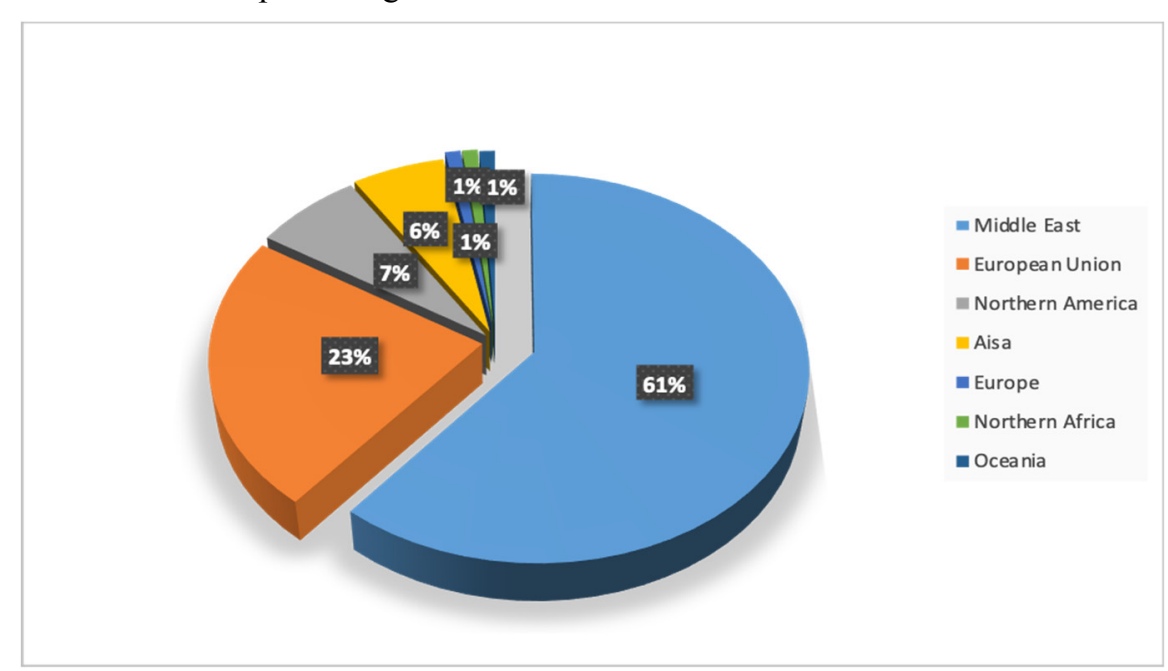

Fig. 2. Regional distribution of top 100 source journals Iranian researchers tend to publish 


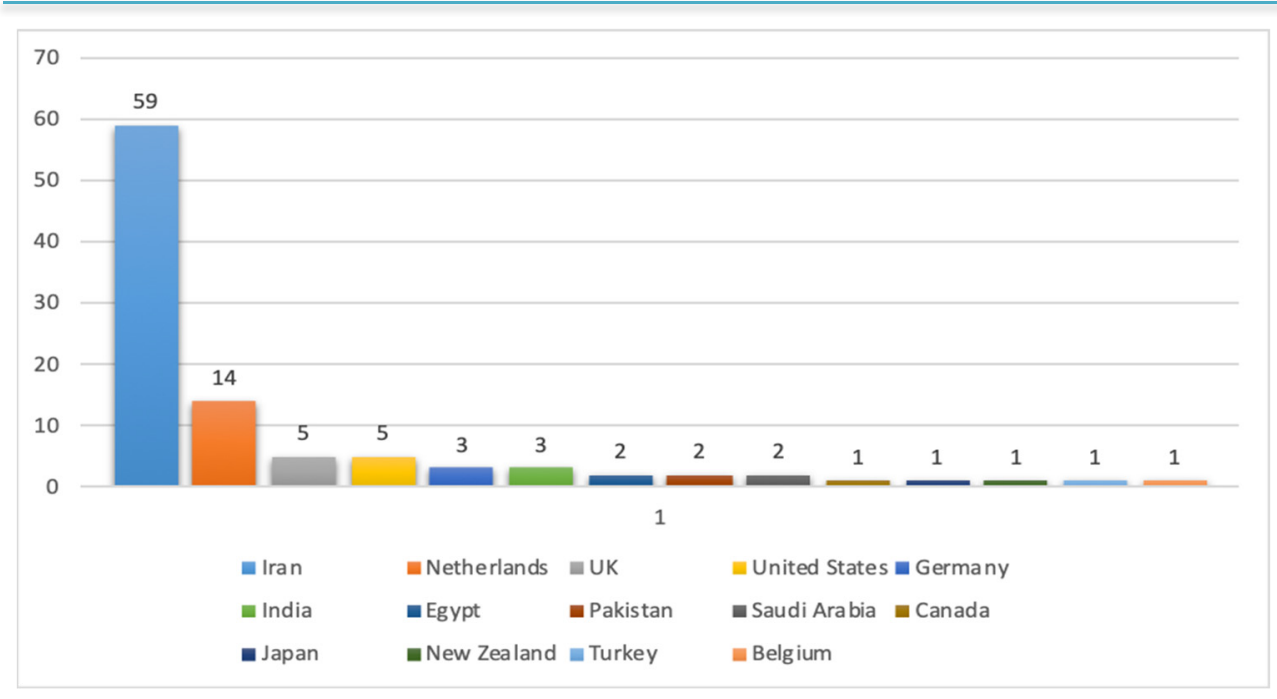

Fig. 3. Country distribution of top 100 source journals

Platform. The highest IF belonged to the journal of "Biosensors \& Bioelectronics" ( $\mathrm{IF}=7.78)$ from Elsevier and $0.004 \%$ of the papers (175 out of 106226 ) were published in it. The average IF of the top 100 source journals was 2.1 . Sixty-one journals $(61 \%)$ were ranked in quartile $3(\mathrm{Q} 3)$ and quartile 4 (Q4) in WoS.

2.2 Scopus analysis: Eighty-seven of the top 100 source journals were indexed in Scopus. As demonstrated in Figure 4, category of "General Medicine" with 25\% has the highest contribution, "Public Health" (4\%), and "Analytical Chemistry" (2\%) respectively. The CiteScore of 53 journals (out of 87) which indexed in Scopus were higher than 1.00 and "Biosensors \& Bioelectronics" journal obtained the highest CiteScore (7.22). The average CiteScore of journals was 1.75 .

Twenty-two percent of journals indexed in Scopus were ranked in Q1 based on CiteScore Percentile. The CiteScore Percentile of two journals; "Journal of Hazardous Materials" and "Biosensors \& Bioelectronics", were 99\%; which means that they are in top one percent in their fields, however only $0.01 \%$ of total papers (568 of 106226 ) were published in these two journals.

The H-index of top 100 source journals ranged between 0 and 218. The highest H-index (218) belonged to "PLOS One" published by Elsevier and the lowest (0) was for "Iranian Journal of Neurology" published by "Tehran University of Medical Sciences". The average H-index was 46.2.

2.3 Status of Iranian journals among top 100 source journals: Fifty-nine titles of the source journals were published in Iran, which included $67 \%$ of total published articles (26 978 of 106 226) in PubMed. In other word, Iranian scholars

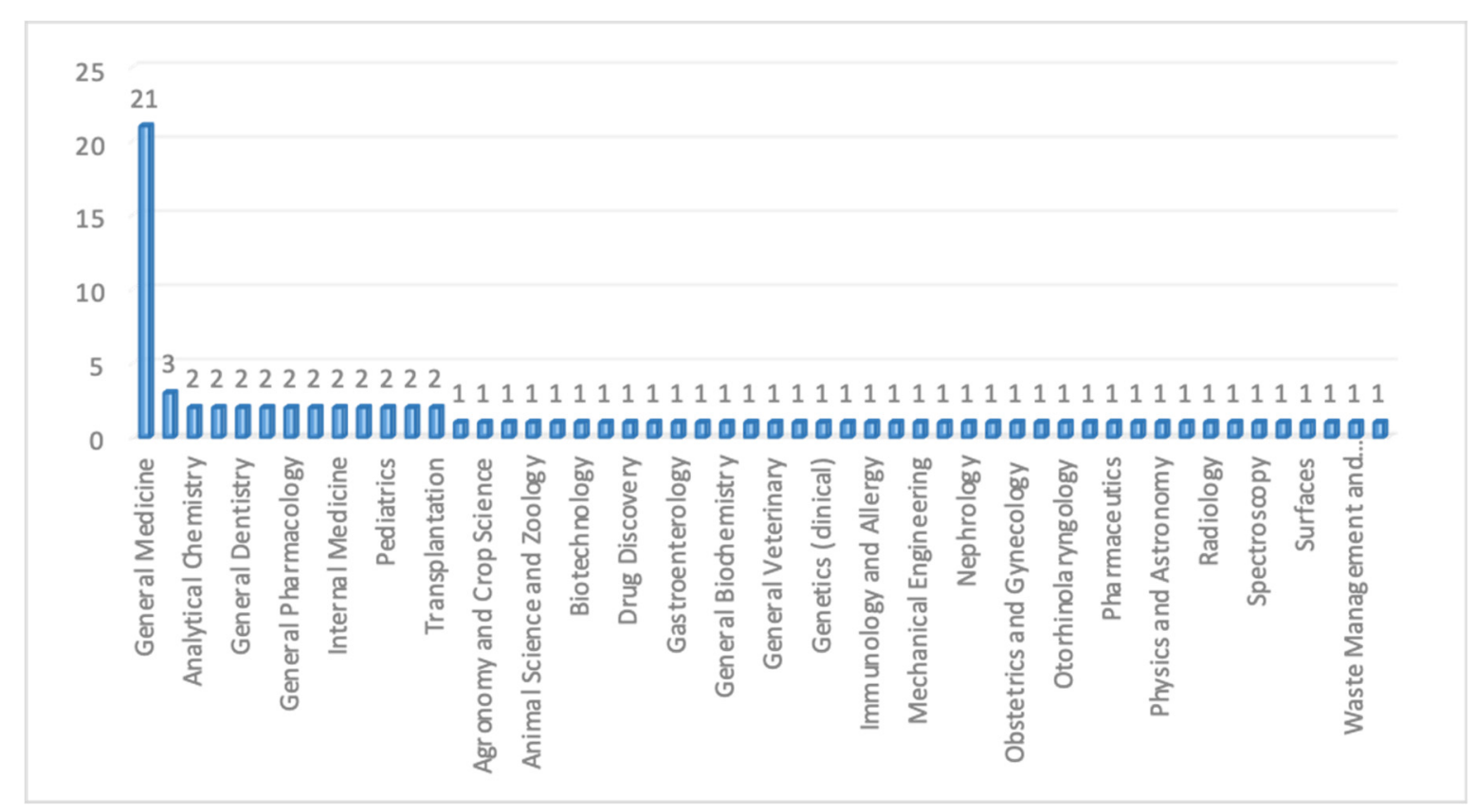

Fig. 4. Category distribution of top 100 source journals 


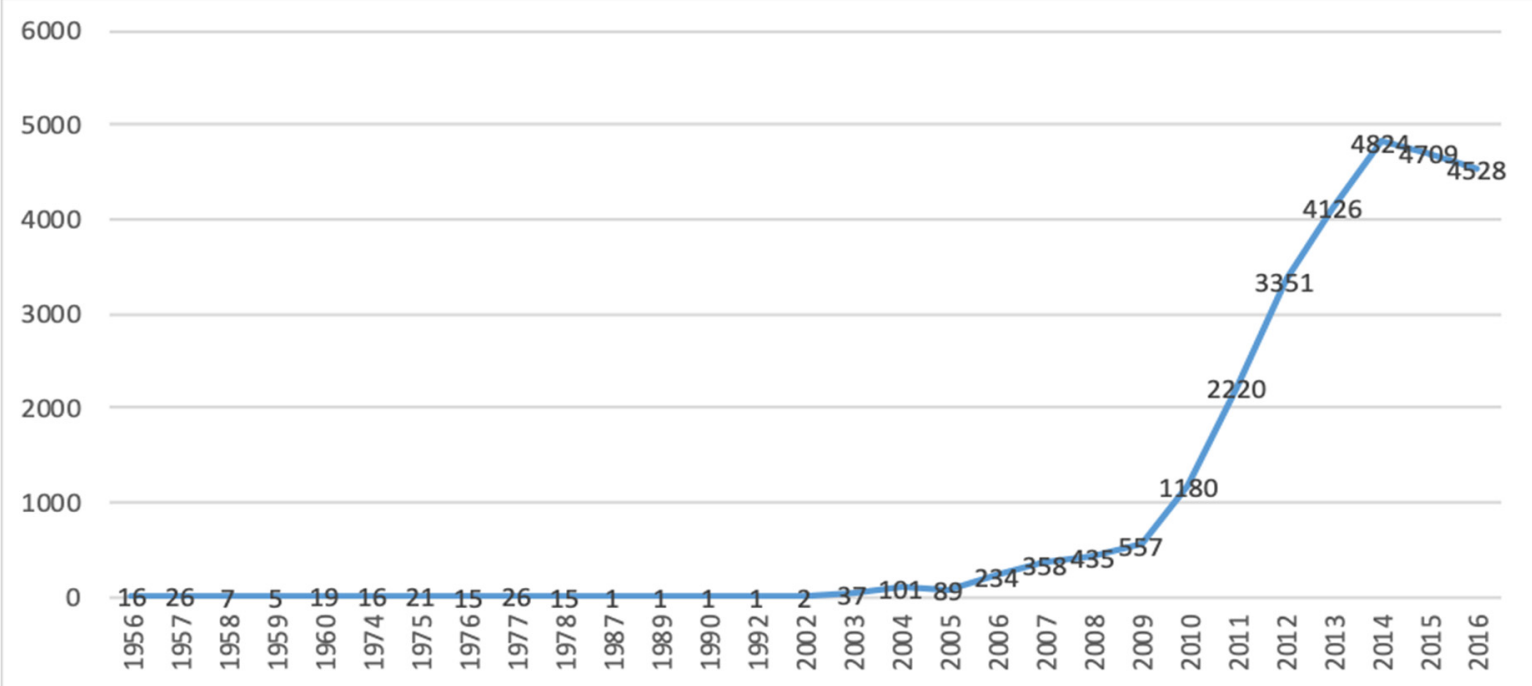

Fig. 5. The trend of Iranian publications in local journals from 1956 to 2016

often tend to publish their papers in local journals rather than other countries. As illustrated in Figure 5, Iranian scholars started to publish in local journals from 1956 in the Acta Medica Iranica which is the oldest scientific medical journal of the country in English language (24). Evidence showed the growing tendency to publish in local journals which tripled in 2003 and doubled between 2009 and 2010.

Despite $63 \%$ (37 of 59) of Iranian journals were indexed in WoS, only 26 journals (38\%) had IF. The highest IF was 2.5 related to "Asian Pacific Journal of Cancer Prevention: APJCP" and the average IF was 1.1. All of the 59 journals were in Q3 and Q4 of WoS ranking.

Eighty percent (47 of 59) of Iranian journals were indexed in Scopus. The highest CiteScore was 2.1 and obtained by "Advanced Pharmaceutical Bulletin" journal. The average CiteScore was 1.1 and the $\mathrm{H}$-index ranged between 0 and 55 (Average=14.4). Sixty-seven percent of 59 journals were ranked in Q3 and Q4 of Scopus and only 3 journals $(6 \%)$ were in Q1.

2.4. Top prolific journals: $10.92 \%$ of papers published in the top 10 journals (Table 1 ) and all of them published in the Middle Eastern and Asia countries. Eight out of 10 were Iranian local journals and two of them belonged to India and Pakistan. The most of papers (approximately $1.5 \%$ ) were published via "Archives of Iranian Medicine".

\section{Influence of GDP on the scientific productivity}

Iran is the second largest economy in the Middle East and North Africa (MENA) after Kingdom of Saudi Arabia, this is evidenced by Iran's GDP which is US\$ 418.977 billion in 2016 (23) and is estimated to reach US\$ 451 billion in 2020 (25). We found a positive and strong correlation between the GDP and number of publications $(r=.738$, $\mathrm{p}<0.001$ ) using a Pearson's correlation coefficient test, it presented in a scatterplot (Fig. 6).

\section{Discussion}

Most of the previous studies have been conducted in a specific subject, domain, or in the limited time frame. Therefore, in this scientometric study, the quantity and quality characteristics of Iran affiliated documents indexed in PubMed were examined and we visualized a big picture of medical publishing of the country over nearly a century and a half.

The socio-cultural factors in $19^{\text {th }}$ century contributed in emergence of the first Iranian PubMed-indexed paper in

Table 1. The 10 top journals which Iranian authors tend to publish in

\begin{tabular}{|c|c|c|c|c|c|c|c|c|c|c|}
\hline & Journal Name & No of Article & Country & Scopus & $\begin{array}{c}\text { CiteScore } \\
2016\end{array}$ & $\begin{array}{c}\text { Q in } \\
\text { Scopus }\end{array}$ & WoS & $\begin{array}{l}\text { JCR } \\
2016\end{array}$ & IF & $\begin{array}{l}\text { Q in } \\
\text { WoS }\end{array}$ \\
\hline 1 & Archives of Iranian medicine & 1546 & Iran & Yes & 1.26 & $\mathrm{Q} 2$ & Yes & Yes & 1.200 & Q3 \\
\hline 2 & Iranian Red Crescent medical journal & 1425 & Iran & Yes & 1.10 & Q2* & Yes & Yes & 0.865 & Q3* \\
\hline 3 & Iranian journal of public health & 1401 & Iran & Yes & 0.85 & Q3 & Yes & Yes & 0.768 & Q4 \\
\hline 4 & Acta medica Iranica & 1242 & Iran & Yes & 0.72 & Q2* & No & No & - & - \\
\hline 5 & Pakistan journal of biological sciences & 1197 & Pakistan & Yes & 0.77 & Q3 & No & No & - & - \\
\hline 6 & Journal of research in medical sciences & 1168 & Iran & Yes & 1.47 & Q2 & Yes & Yes & 1.237 & Q3 \\
\hline 7 & Iranian journal of pharmaceutical research & 1013 & Iran & Yes & 1.70 & $\mathrm{Q} 1 *$ & Yes & Yes & 1.507 & Q4 \\
\hline 8 & Asian Pacific journal of cancer prevention & 991 & Iran & Yes & 1.87 & Q2 & Yes & Yes & 2.514 & Q3 \\
\hline 9 & Advanced biomedical research & 823 & India & No & - & - & No & No & - & - \\
\hline 10 & Iranian journal of basic medical sciences & 799 & Iran & Yes & 1.63 & Q3キ & Yes & Yes & 1.424 & Q3* \\
\hline
\end{tabular}

Note: Authors double checked the quartiles of the journals after the whole data analysis based on latest Scimago and JCR data, some ranks is changed as specified.

$*$ The quartile fell down one class.

† The quartile improved one class. 


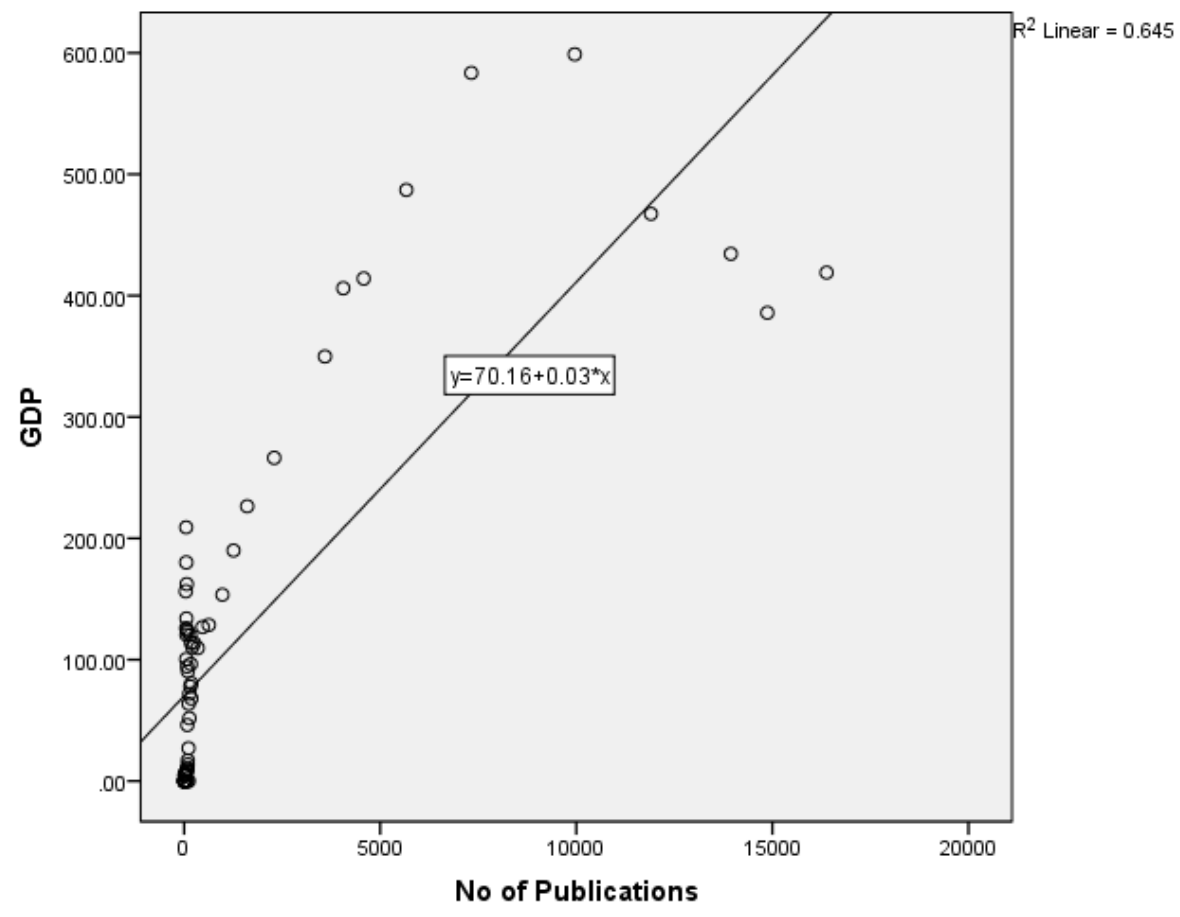

Fig. 6. Correlation between the GDP of Iran and Iranian publications from 1960 to 2016

1877. In this period, relations between Iran and Europe expanded (26) and movement toward modernity was started (27). The long-term publication output trends indicate that contribution to global knowledge production had slow growing rate until 1922 since only six papers published in PubMed by Iran from 1877 to 1922 . It is noteworthy the authors of all six papers was foreigner who worked as researcher in Iran.

From 1922 to 1945 there was a stagnation period in the academic publication. World War I and II and regime changes from Qajar to Pahlavi dynasty occurred between 1914 and $1945(28,29)$, could be the main reasons for publication stagnation for 23 years in Iran.

From 1945, the Iranian scholars restarted academic publishing with slow rate until 2000. During this period, country experienced unstable political relationship due to Islamic revolution occurred in 1979 and Iran-Iraq war (1980988). Therefore, the growth was interrupted and according to Habibi et al report, the number of publications authored or coauthored by Iranian researchers decreased clearly during and consequent upon the long-lasting war (30). The Joint Comprehensive Plan of Action (JCPOA) in July 2015 by Iran and a group of six other countries, with the aim of lifting sanctions against Iran, fueled the hopes for improvement and progress in the scientific and research productions in Iran (31).

As the past studies reported, despite the sanctions against Islamic Republic of Iran, there is increasing rate in number of publications from 2000 to 2016 (343 to 16382 paper) (32). The number of governmental universities, non-governmental institutions (eg, Islamic Azad University), and students, developed in this period (33); thus the number of scientific publication increased, subsequently.

Regardless of the growing number of publications, the
Iranian scholars tend to publish their works in local journals which categorized in Q3 and Q4 of Scopus and WoS rank, thus the quality is questionable. This finding is consistent with Mansoori and Sadeh et al. results that Iranian researchers have high contribution in the journals with low IF (17, 34).

Similarly, the reports show that although the titles of Iranian medical journals approved by Commission for Accreditation and Improvement of Iranian Medical Journals (CAIMJ) increased over the past 10 years (from 113 journals in 2007 to 212 in 2011, and 415 titles in 2018), the quality improvement of journals is slow, whereas only $2 \%$ of Iranian medical journals were indexed in WoS and Scopus in 2007 . The rate increased to $12 \%$ (26 of 212 ) for journals indexed in WoS and 39\% (82 of 212) for Scopus in 2011. Even though the quantity is doubled in 2018, the number of journals indexed in WoS increased only $5 \%$ (from $12 \%$ in 2011 to $17 \%$ in 2018) and the percentage of Iranian Scopus journals dropped from $39 \%$ in 2011 to $25 \%$ in $2018(35,36)$. Davarpanah also reported the low visibility of the local journals. Consequently, the number of citations can affect and falls under the visibility limitation (37). An increasing tendency to publish in local journals with less credibility is the dark side of scientific production in Iran.

Further studies should be conducted to investigate the cause and effect of publishing in low ranked local journals. Nevertheless, in most of Iranian universities, quantitative criteria, e.g. number of documents published in prestigious databases such as PubMed, WoS, or Scopus, are the mere tools to evaluate the research performance of researchers (38). Consequently Iranian researchers tend to publish in journals with high acceptance rate (34). Other studies suggest that Iranian scholars are the main contributors to the 
predatory journals (39) and the country seemed to be the origin of a relatively large number of papers and authors in predatory journals according to Research Papers in Economics (RePEc) archives published in 2015 (40).

Further evaluation revealed that there is a strong effect of GDP on scientific output in Iran. This resembles the findings reported in the past literature (41-45).

The time for scientific flourishing in Iran was shortened since the United States left the Iran nuclear deal and re-imposed sanctions against Iran in 2018. Based on previous studies, sanctions have had negative impact on the quantity and quality of publications in Iran because of accessibility to the scholarly works as well as limitations in the scientific collaboration between Iran and international researchers (46), purchasing laboratory materials and equipment (47) and the other economic problems caused by sanctions.

Overall, while the quantity of Iranian medical papers is remarkably significant, based on the country's publishing pattern, quality-related issues need to be investigated further to improve.

Limitations: The study had two limitations. First, since the GDP data was introduced from 1945, we selected the mirror publication data for correlation test and the data before 1945 were excluded in the related analysis. The second limitation originate from the PubMed indexing method which some of the papers may appear later. Although research data were extracted in January 2018 it is likely to say that some data were missed in current study.

\section{Conclusion}

This is the first study with panorama view of the medical publishing in Iran, one of the largest economies in the world in terms of natural oil and gas reserves. We discussed that a significant positive trend exists for PubMed indexed documents in Iran and the GDP growth has had positive influence on quantity of publications. However, more than half of journals which Iranian scholars tend to publish, were categorized into Q3 and Q4 rank of WoS and Scopus. The Iranian medical research policy-makers are encouraged to support revising the tenure and promotion criteria of faculty members and researchers as a result the Iranian scholars will concentrate quality of their publications rather than quantity.

\section{Conflict of Interests}

The authors declare that they have no competing interests.

\section{References}

1. Durieux V, Gevenois PA. Bibliometric indicators: quality measurements of scientific publication. Radiology. 2010;255(2):34251.

2. Judge TA, Cable DM, Colbert AE, Rynes SL. What causes a management article to be cited-article, author, or journal? Acad Manage J. 2007;50(3):491-506.

3. Brembs B, Button K, Munafo M. Deep impact: unintended consequences of journal rank. Front Hum Neurosci. 2013;7:291.

4. Kharabaf S, Abdollahi M. Science growth in Iran over the past 35 years. J Res Med Sci. 2012;17(3):275.

5. Valderas JM. Why Do Team-Authored Papers Get Cited More? Science. 2007;317(5844):1496-8.

6. van Raan A, Visser M, Van Leeuwen T, van Wijk E. Bibliometric analysis of psychotherapy research: performance assessment and position in the journal landscape. Psychother Res. 2003;13(4):511-28.

7. Bornmann L, Schier H, Marx W, Daniel HD. What factors determine citation counts of publications in chemistry besides their quality? J Informetr. 2012;6(1):11-8.

8. Gul S, Nisa NT, Shah TA, Gupta S, Jan A, Ahmad S. Middle East: research productivity and performance across nations. Scientometrics. 2015;105(2):1157-66.

9. Akyüz ZC, Correia RA. A Bibliometric Analysis of High Impact Research in the Middle East Using Champion Works. Int Inform Libr Rev. 2017;49(1):11-8.

10. Kharabaf S, Abdollahi M. Science growth in Iran over the past 35 years. J Res Med Sci. 2012;17(3):275-9.

11. Osareh F, Wilson CS. Collaboration in Iranian scientific publications. Libri. 2007;52(2):88-98.

12. Atta Ur R, Nasim A. Time for 'enlightened moderation'. Nature. 2004;432(7015):273-4.

13. Naghizadeh M, Naghizdeh R. Growth of scientific publications in Iran: Reasons, impacts, and trends. The Development of Science and Technology in Iran: Springer; 2017. p. 75-86.

14. Saboury A. Research report status of Iran in 2002. Rahyaft. 2003;28:87-95

15. Moin M, Mahmoudi M, Rezaei N. Scientific output of Iran at the threshold of the 21st century. Scientometrics. 2005;62(2):239-48.

16. Malekzadeh R, Azarakhsh Mokri M, Azarmina P. Medical science and research in Iran. Arch Irn Med. 2001;4(1):28.

17. Sadeh S, Mirramezani M, Mesgaran MB, Feizpour A, Azadi P. (2019). The Scientific Output of Iran: Quantity, Quality and Corruption Working Paper 7, Stanford Iran 2040 Project, Stanford University.

18. Publication Characteristics (Publication Types) with Scope Notes; 2018 MeSH Pubtypes: U.S. National Library of Medicine; [Dec 2018] Available from: https://www.nlm.nih.gov/mesh/pubtypes.html.

19. Baker RL, editor Persia Becomes Iran. Current History and Forum; 1935: $\mathrm{CH}$ publishing corporation, etc.

20 Farnen RF. Political culture, socialization, democracy and education: interdisciplinary and cross-national perspectives for a new century (Vol 7). Peter Lang Publishing. 2008

21. Lucas. Case of scleroderma. Ind Med Gaz. 1877;12(8):211.

22. Baltazard M, Ghodssi M. Prevention of human rabies; treatment of persons bitten by rabid wolves in Iran. Bull World Health Organ 1954;10(5):797-803.

23. GDP of Iran, Islamic Rep. : The World Bank Group; 2018 [Dec 2018]. Available from: https://tradingeconomics.com/iran/forecast.

24. Acta Medica Iranica: Tehran University of Medical Sciences; [May 2020]. Available from: http://acta.tums.ac.ir/index.php/acta.

25. Economic Forecasts for Iran: Trading Economics; 2018 [Dec 2018]. Available from: https://tradingeconomics.com/iran/forecast.

26. de Bruijn JTP. Persian literature2015 June 19, 2018. Available from: https://www.britannica.com/art/Persian-literature/Classical-prose.

27. Roshanfekr Joursharia M, Roshanfekr Jourshari S, Najafgholi Pour Kalantari N. Studying the effects of modernity on development of Iranian architecture in the Qajar Era. International Comprehensive Competition Conference on Engineering Science In Iran; Anzali, Iran: University of Guilan; 2016.

28. Keegan J. The first world war2014 June 19, 2018 Dec 2018]. Available from: $\quad \mathrm{http}: / / \mathrm{www}$. firstworldwar.com/features/germany duringww $1 . h t m$.

29. Gilbert M, Mayes B. The second world war: A complete history: H. Holt; 1989.

30. Habibi G, Rashidi A, Feldman MD. Emerging concerns about Iran's scientific and medical future. Lancet. 2006;9540(368):985.

31. Mozafari M. Iran and science publishing in the post-sanctions era. Lancet. 2016;387(10029):1721-2.

32. Lankarani KB, Haghdoost A, Smith P. Embargo on publication of scientific papers by Iranian authors. Lancet. 2012;380(9842):648-9.

33. Bazargan A. Internal evaluation as an approach to revitalize university systems: the case of the Islamic Republic of Iran. High Educ Pol. 2000;13(2):173-80

34. Mansoori P. 50 years of Iranian clinical, biomedical, and public health research: a bibliometric analysis of the Web of Science Core Collection (1965-2014). J Glob Health. 2018;8(2):020701.

35. Rezaeian M, Hadavi M, Bakhtar M, Davvodi Salestani A, Karimeian M. Evaluation the quality of english and persian journals approved by commission for accreditation and improvement of Iranian medical journals (CAIMJ) in 2011: Successes and challenges. J Rafsanjan Univ 
Med Sci. 2014;13(2):163-74.

36. CAIMJ. About the Commission Tehran, Iran: Commission for Accreditation and Improvement of Iranian Medical Journals 2018 [Dec 2018]. Available from: https://journals.research.ac.ir/page $/ 11 / \%$ D8\%AF\%D8\%B1\%D8\%A8\%D8\%A7\%D8\%B1\%D9\%87-\%DA $\%$ A 9\%D9\%85\%DB\%8C\%D8\%B3\%DB\%8C\%D9\%88\%D \% $\% 86$.

7. Davarpana MR, Behrouzfar H. International visibility of Iranian ISI journals: A citation study. Aslib Proc. 2009;61(4):407-19.

38. Beall J. Essential information about predatory publishers and journals. Int High Educ. 2016(86):2-3.

39. Shen C, Björk BC. 'Predatory' open access: a longitudinal study of article volumes and market characteristics. BMC Med. 2015;13(1):230.

40. Wallace FH, Perri TJ. Economists behaving badly: publications in predatory journals. Scientometrics. 2018;115(2):749-66.

41. Oelrich B, Peters R, Jung K. A Bibliometric Evaluation of Publications in Urological Journals among European Union Countries between 20002005. Eur Urol. 2007;52(4):1238-48.

42. Fan G, Han R, Zhang H, He S, Chen Z. Worldwide Research Productivity in the Field of Minimally Invasive Spine Surgery: A 20year Survey of Publication Activities. Spine. 2017;42(22):1717-22.

43. Wiysonge CS, Uthman OA, Ndumbe PM, Hussey GD. A bibliometric analysis of childhood immunization research productivity in Africa since the onset of the Expanded Program on Immunization in 1974. BMC Med. 2013;11:66.

44. Niu B, Hong S, Yuan J, Peng S, Wang Z, Zhang X. Global trends in sediment-related research in earth science during 1992-2011: a bibliometric analysis. Scientometrics. 2014;98(1):511-29.

45. Senel E, Demir E. A global productivity and bibliometric analysis of telemedicine and teledermatology publication trends during 1980-2013. Dermato Sin. 2015;33(1):16-20.

46. Adab P, Mavaddat N, Lee C, Foroughi M, Lilford RJ. Post-sanctions era in Iran: opportunity for science and publication. Lancet. 2016;388(10039):28-9.

47. Zahediasl S. Iran and science publishing: an open letter. Lancet. 2013;382(9892):596. 
Appendix 1. Top 100 source journals' data published the most Iranian papers in PubMed

\begin{tabular}{|c|c|c|c|c|}
\hline & Journal Title & No of Articles & ISSN & Country \\
\hline 1 & Archives of Iranian medicine & 1546 & $1029-2977$ & Iran \\
\hline 2 & Iranian red crescent Medical journal & 1425 & 2074-1804 & Iran \\
\hline 3 & Iranian journal of public health & 1401 & $0304-4556$ & Iran \\
\hline 4 & Acta medica Iranica & 1242 & $0044-6025$ & Iran \\
\hline 5 & Pakistan journal of biological sciences & 1197 & $1028-8880$ & Pakistan \\
\hline 6 & Journal of research in medical sciences & 1168 & $1735-1995$ & Iran \\
\hline 7 & Iranian journal of pharmaceutical research & 1013 & $1735-0328$ & Iran \\
\hline 8 & Asian Pacific journal of cancer prevention & 991 & $1513-7368$ & Iran \\
\hline 9 & Advanced biomedical research & 823 & $2277-9175$ & India \\
\hline 10 & Iranian journal of basic medical sciences & 799 & $2008-3866$ & Iran \\
\hline 11 & International journal of preventive medicine & 783 & $2008-7802$ & Iran \\
\hline 12 & Iranian journal of pediatrics & 751 & $2008-2142$ & Iran \\
\hline 13 & Iranian journal of kidney diseases & 732 & $1735-8582$ & Iran \\
\hline 14 & Iranian journal of nursing and midwifery research & 656 & $2228-5504$ & Iran \\
\hline 15 & Spectrochimica acta. Part A, Molecular and biomolecular spectroscopy & 624 & $1386-1425$ & UK \\
\hline 16 & Iranian journal of allergy, asthma, and immunology & 621 & $1735-1502$ & Iran \\
\hline 17 & Iranian journal of medical sciences & 567 & 0253-0716 & Iran \\
\hline 18 & Eastern Mediterranean health journal & 563 & $1020-3397$ & Egypt \\
\hline 19 & Talanta & 562 & 0039-9140 & Netherlands \\
\hline 20 & Medical journal of the Islamic Republic of Iran & 558 & $1016-1430$ & Iran \\
\hline 21 & Global journal of health science & 530 & $1916-9736$ & Canada \\
\hline 22 & Iranian journal of parasitology & 498 & $1735-7020$ & Iran \\
\hline 23 & Iranian journal of reproductive medicine & 471 & $1680-6433$ & Iran \\
\hline 24 & Jundishapur journal of microbiology & 467 & $2008-3645$ & Iran \\
\hline 25 & Urology journal & 467 & $1735-1308$ & Iran \\
\hline 26 & Plose One & 466 & $1932-6203$ & United States \\
\hline 27 & Iranian endodontic journal & 451 & $1735-7497$ & Iran \\
\hline 28 & Transplantation proceedings & 442 & $0041-1345$ & United States \\
\hline 29 & Hepatitis monthly & 413 & $1735-143 X$ & Iran \\
\hline 30 & Journal of hazardous materials & 411 & 0304-3894 & Netherlands \\
\hline 31 & Journal of dentistry & 396 & $1735-2150$ & Iran \\
\hline 32 & Materials science \& engineering. C, Materials for biological applications & 396 & $0928-4931$ & Netherlands \\
\hline 33 & International journal of biological macromolecules & 389 & $0141-8130$ & Netherlands \\
\hline 34 & Journal of ophthalmic \& vision research & 378 & $2008-2010$ & Iran \\
\hline 35 & Dental research journal & 373 & $1735-3327$ & Iran \\
\hline 36 & Iranian journal of microbiology & 363 & 2008-3289 & Iran \\
\hline 37 & Iranian journal of radiology & 359 & $1735-1065$ & Iran \\
\hline 38 & Electronic physician & 350 & $2008-5842$ & Iran \\
\hline 39 & Iranian biomedical journal & 350 & $1028-852 \mathrm{X}$ & Iran \\
\hline 40 & Saudi journal of kidney diseases and transplantation & 349 & $1319-2442$ & Saudi Arabia \\
\hline 41 & Environmental monitoring and assessment & 337 & $0167-6369$ & Netherlands \\
\hline 42 & Cell journal & 330 & $2228-5806$ & Iran \\
\hline 43 & Ultrasonics sonochemistry & 328 & $1350-4177$ & Netherlands \\
\hline 44 & Journal of education and health promotion & 327 & $2319-6440$ & Iran \\
\hline 45 & Iranian journal of immunology & 322 & $1735-1383$ & Iran \\
\hline 46 & Analytica chimica acta & 317 & $0003-2670$ & Netherlands \\
\hline 47 & Saudi medical journal & 317 & $0379-5284$ & Saudi Arabia \\
\hline 48 & ARYA atherosclerosis & 308 & $1735-3955$ & Iran \\
\hline 49 & Journal of dental research, dental clinics, dental prospects & 308 & $2008-210 X$ & Iran \\
\hline 50 & Advanced pharmaceutical bulletin & 291 & $2251-7308$ & Iran \\
\hline 51 & Caspian journal of internal medicine & 276 & $2008-6164$ & Iran \\
\hline 52 & Daru : journal of faculty of pharmacy & 266 & $1560-8115$ & Iran \\
\hline 53 & Zootaxa & 266 & $1175-5326$ & New Zealand \\
\hline 54 & Anesthesiology and pain medicine & 265 & $2228-7523$ & Netherlands \\
\hline 55 & Iranian journal of otorhinolaryngology & 262 & $2251-7251$ & Iran \\
\hline 56 & European journal of pharmacology & 259 & 0014-2999 & Netherlands \\
\hline 57 & Iranian journal of psychiatry & 254 & $1735-4587$ & Iran \\
\hline 58 & The journal of Tehran heart center & 254 & $1735-8620$ & Iran \\
\hline 59 & Physical review. E, Statistical, nonlinear, and soft matter physics & 250 & $1539-3755$ & United States \\
\hline 60 & Iranian journal of cancer prevention & 246 & $2008-2398$ & Iran \\
\hline
\end{tabular}




\begin{tabular}{|c|c|c|c|c|}
\hline & Journal Title & No of Articles & ISSN & Country \\
\hline 61 & Journal of separation science & 245 & $1615-9306$ & Germany \\
\hline 62 & Veterinary research forum & 245 & $2322-3618$ & Iran \\
\hline 63 & Journal of research in health sciences & 243 & $2228-7795$ & Iran \\
\hline 64 & Iranian journal of neurology & 241 & $2252-0058$ & Iran \\
\hline 65 & Journal of chromatography. A & 239 & $0021-9673$ & Netherlands \\
\hline 66 & The scientific world journal & 239 & $1537-744 \mathrm{X}$ & Egypt \\
\hline 67 & Molecular biology reports & 237 & $0301-4851$ & Netherlands \\
\hline 68 & Gastroenterology and hepatology from bed to bench & 232 & $2008-2258$ & Iran \\
\hline 69 & International journal of fertility \& sterility & 230 & 2008-076X & Iran \\
\hline 70 & Middle East journal of digestive diseases & 220 & $2008-5230$ & Iran \\
\hline 71 & Iranian journal of psychiatry and behavioral sciences & 219 & $1735-8639$ & Iran \\
\hline 72 & Research in pharmaceutical sciences & 219 & $1735-5362$ & Iran \\
\hline 73 & The Journal of the Pakistan medical association & 218 & 0030-9982 & Pakistan \\
\hline 74 & Journal of clinical and diagnostic research & 216 & 0973-709X & India \\
\hline 75 & Trauma monthly & 216 & $2251-7464$ & Iran \\
\hline 76 & Journal of parasitic diseases : official organ of the Indian Society for Parasitology & 212 & 0971-7196 & India \\
\hline 77 & Tanaffos & 210 & $1735-0344$ & Iran \\
\hline 78 & Iranian journal of child neurology & 209 & $1735-4668$ & Iran \\
\hline 79 & Journal of diabetes and metabolic disorders & 201 & $2251-6581$ & Iran \\
\hline 80 & Avicenna journal of phytomedicine & 196 & $2228-7930$ & Iran \\
\hline 81 & Journal of environmental health science \& engineering & 195 & $2052-336 X$ & UK \\
\hline 82 & Avicenna journal of medical biotechnology & 194 & $2008-2835$ & Iran \\
\hline 83 & Biological trace element research & 191 & $0163-4984$ & United States \\
\hline 84 & Journal of dentistry & 188 & $2345-6485$ & Iran \\
\hline 85 & Nephro-urology monthly & 187 & $2251-7006$ & Netherlands \\
\hline 86 & Food chemistry & 184 & $0308-8146$ & Netherlands \\
\hline 87 & Journal of colloid and interface science & 181 & 0021-9797 & United States \\
\hline 88 & Carbohydrate polymers & 180 & $0144-8617$ & UK \\
\hline 89 & $\begin{array}{c}\text { Experimental and clinical transplantation : official journal of the Middle East Soci- } \\
\text { ety for Organ Transplantation }\end{array}$ & 180 & $1304-0855$ & Turkey \\
\hline 90 & Journal of cardiovascular and thoracic research & 177 & $2008-5117$ & Iran \\
\hline 91 & Biosensors \& bioelectronics & 175 & 0956-5663 & UK \\
\hline 92 & Journal of medical signals and sensors & 174 & $2228-7477$ & Iran \\
\hline 93 & $\begin{array}{l}\text { Tumour biology: the journal of the international society for oncodevelopmental biol- } \\
\text { ogy and medicine }\end{array}$ & 171 & $1010-4283$ & Germany \\
\hline 94 & $\begin{array}{c}\text { Analytical sciences: the international journal of the Japan society for analytical } \\
\text { chemistry }\end{array}$ & 169 & $0910-6340$ & Japan \\
\hline 95 & Communications in agricultural and applied biological sciences & 169 & $1379-1176$ & Belgium \\
\hline 96 & Colloids and surfaces. B, Bio interfaces & 168 & $0927-7765$ & Netherlands \\
\hline 97 & Natural product research & 168 & $1478-6419$ & UK \\
\hline 98 & Addiction \& health & 167 & $2008-4633$ & Iran \\
\hline 99 & Parasitology research & 167 & 0932-0113 & Germany \\
\hline 100 & Journal of caring sciences & 164 & $2251-9920$ & Iran \\
\hline
\end{tabular}

